\title{
The Wave Properties of Zuara Coast and Their Effects on the Marine Navigation
}

\author{
Jamal Algraeo $^{1 *}$, Samir Bouaziz ${ }^{2}$ \\ ${ }^{1}$ Geography Department, College of Arts, Azzawia University, Subratah, Libya \\ ${ }^{2}$ Geology Department, National Engineering School, Sfax University, Sfax, Tunisia \\ Email: *jamal_om2000@yahoo.com, samir.bouaziz@enis.rnu.tu
}

Received December 9, 2012; revised March 4, 2013; accepted March 17, 2013

Copyright (C 2013 Jamal Algraeo, Samir Bouaziz. This is an open access article distributed under the Creative Commons Attribution License, which permits unrestricted use, distribution, and reproduction in any medium, provided the original work is properly cited.

\begin{abstract}
Waves are the most important phenomena affecting marine navigation, either in the field of fishing, military or transporting of goods. This paper tries to answer the following important questions: What are the causes and types of waves in the coast of Zuara city? What are their characteristics? And how do those waves affect the marine navigation and human activities on this coast? The research finds significant results devoted in that: the coast is exposed to on type of waves; wind waves. Zuara coast has never been exposed to waves of Tsunami or landslides. The largest size of the wave forms in winter season due to the wind of north-west which is the fastest wind type that the Libyan coast is exposed to. However, the highest speed is up to 65 knots accompanied with waves reach a height of more than 7 meters. The research also classifies the wind speeds that lead to cancelling ships and boats trips that depend on this work is studying the waves in Zuara coast and the relationship with the waves of Libyan coast and Mediterranean sea. Also, it focuses on the effect of waves on boat speed, design, fuel consumption, and other effects.
\end{abstract}

Keywords: Zuara Coast; Marine Navigation; Wind Waves; Dimensions Waves; Marine Human Activities

\section{Introduction}

Waves are the circular movement of water molecules that makes the water surface turbulent and makes floating bodies in vertical persistent movement, which does not stop until the waves calm. On this basis, the waves affect the activity of humans who ride the sea, and this causes increasing in the size of waves, leading in many cases to stop the activity and the cancelling of a lot of cruises for the reason of fear or cut the risk of adventure to challenge the sea waves.

Hence, it can be seen that the most human activities affected by the waves are: marine navigation, transport of goods, passengers on ships, fishing and military activities. All these activities are in need to the nature of waves in order to perform their duties. And therefore, specialists in all mentioned areas, to know about the properties of waves in coats that they use in their activities in terms of navigation and the sizes, causes and types of the waves, as well as the time that waves occur, so that they can avoid dangers which sometimes lead to lack of human lives [1].

And because of the Coast of Zuara city has shipping

${ }^{*}$ Corresponding author. activity which is distinct from the neighboring coast that contains a port for cargo and fishing, so the waves should be studied deeply to find out their nature, size and other characteristics so can be dealt with in a proper way. This paper focuses on the properties of the waves, on their nature and impacts on human activities.

Zuara coast is located to the north-west of Libya longitude $12^{\circ} 04^{\prime} 45 \mathrm{E}$ and latitude $32^{\circ} 56^{\prime} 3 \mathrm{~N}$, limits Zuara to the north Mediterranean Sea (Figure 1), and west of the Libyan capital city (Tripoli) about $100 \mathrm{~km}$.

However, the study also examines the relationship of waves with the maritime navigation in the coast of Zuara city and tries to answer the following questions:

Q1: What are the causes and types of waves?

Q2: What are the properties of waves in the coast of Zuara city?

Q3: How do waves affect marine navigation?

On this basis, some objectives appear which are: studying the causes and types of waves, knowing the nature of the waves in terms of dimensions and times to find out the impact of waves on marine navigation.

The researcher has followed several methods and approaches to reach the objectives of the study, which are the statistical method for dealing with meteorological data, 


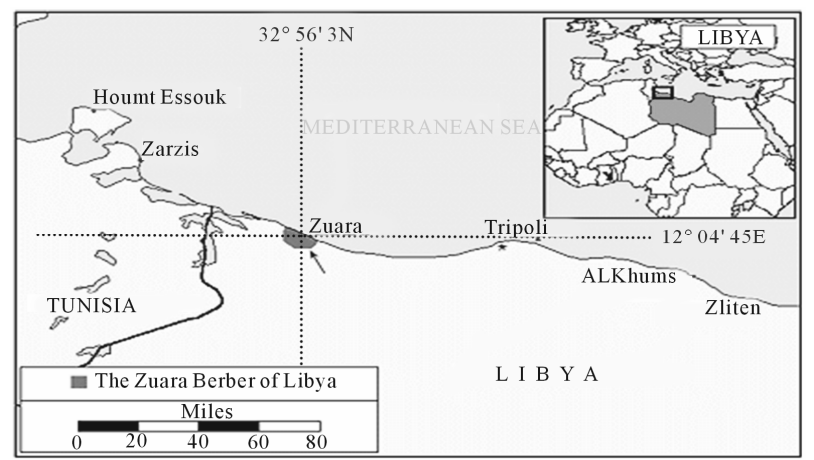

Figure 1. Zuara city locations [2].

the descriptive approach and field visits.

This study is an initial step to open search in this kind of few studies in the country, and this is what induces me to investigate in this area of research.

\section{The Concept of Wave and Its Dimensions and Types}

Wave is defined as the regular height (convexity) and depression (concavity) in the water surface. This is called a waved relating to the wave [3].

On this basis, a wave has several dimensions as shown in Figure 2:

A-Bottom of the wave (trough), which is the lowest point in the concavity posed by the depression of water surface.

$\mathrm{B}$ - The top of the wave (crest), which is the highest point in the convexity posed by the rising water.

$\mathrm{C}$-Wave height: the distance between the bottom of the wave and its peak, because the wave falls below sea level and rises the same distance depression.

$\mathrm{D}$-Wave length: the distance between two crests or two troughs and there is an inverse relationship between wave height and length that as length increases the height decrease.

E-Wave amplitude, a widening distance between the overall level of water surface in a calm sea, and the crest of the wave. This is important especially in the case of specifying the height of the industrial jetties in ports.

F-Wave period: the time it takes for peaks to pass a fixed point [4].

$\mathrm{G}$-Wave steepness is the percentage of wave height to the wave length $\mathrm{H} / \mathrm{L}$, and in deep water the wave does not contain the decline greater than $1 / 7$ without a breakage, but in some times waves may decline slightly bigger than this value. Waves can't have appointed top angle more than $120^{\circ}$ (Figure 3) without breaking [5].

\section{The Waves Causes}

Waves happen by several causes or factors, namely:

1) Landslides, mudslides or the collapse of dams;

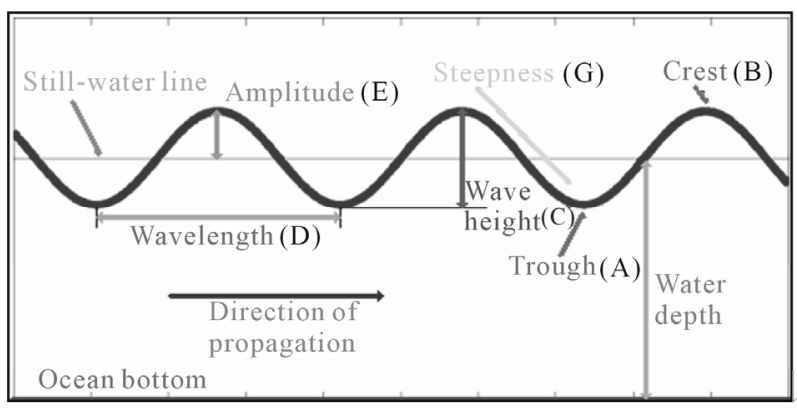

Figure 2. Dimensions of a wave [6].

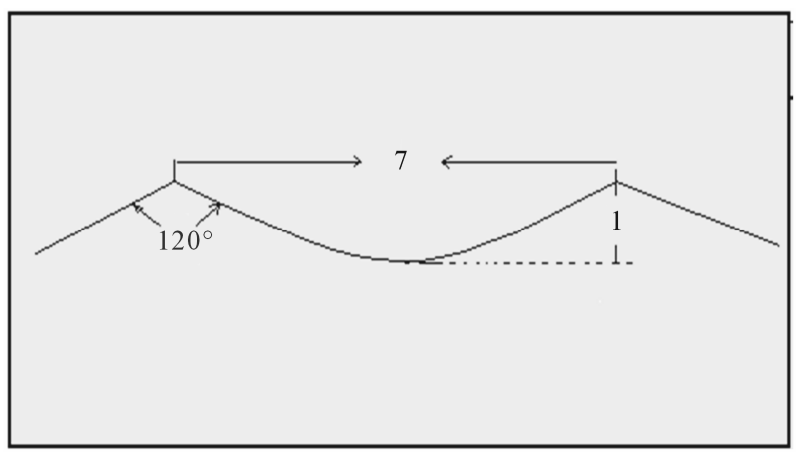

Figure 3. Wave can not have a pointed top or decline of more than $7 / 1$, without break.

2) Earth quakes and volcanoes that happen at sea and produce the so-called tsunami;

3) Winds, storms and hurricanes.

\subsection{Landslides, Mud Slides and the Collapse of Dams}

Landslides, which happen in the relatively small water bodies cause destructive waves. On 9 October 1963, for example-Italy has seen the catastrophe collapse of huge clay blocks in the basin of (Fayont) dam, which led to the formation of waves 90 meters high in outrageous release to a distance of 1.5 kilometers towards the lower valley devastating everything in its way [7].

But such waves are rare to occur and non-observable only if they occur in relatively small lakes or rivers so they will not get the detailed attention, especially as their occurrence in the sea is ineffective.

\subsection{The Seismic Waves (Tsunami)}

Earth is subject to about one million earthquakes a year. People mostly do not feel them because either they are weak or occur in unpopulated areas. Usually human feel the earthquake only when its magnitude up to 4 on the Richter scale, and is considered a major earthquake when its strength is more than 7 degrees on this scale.

When marine earthquakes occur, sea water dominated by giant waves, which called the "Tsunami”. Tsunami is 
a Japanese word originally means the tidal waves, but these waves are not related to tidal, so specialists call it "Seismic waves" relative to the earthquakes [8]. Also tsunami means port waves (perhaps because the ports are more susceptible to these waves).

These waves are built up in the deep sea water, and attack the coast pour about 100 thousand tons of water on every square meter of the beach and thus lead to greater losses than the damage caused by the earthquake itself.

Tsunami waves are generated by a volcanic eruption, earthquake on the ocean bottom surface, landslides in the bottom, or a land collision with cosmic body generating a violent jolt. These all lead to an offset section of the sea water which creates a turbulence changing into giant waves.

There are changes occurring in the bottom of the seas and oceans, leading to movement of the land surface and the emergence of cracks in the bottom of the sea caused by earthquakes and volcanoes (Figure 4). When there is displacement or land subsidence in part of the ocean bottom surface, this leads to format an empty space that quickly filled with water, and as a result of quick flow of water toward the bottom to fill the space, this makes the water flows away from the coast, and according to fluid mechanics engineering to bounce in reverse direction of flow of water, where a rush of large amounts of water from the ocean bottom surface upward as a result of back reaction on the water speed. These amounts of water surging up causing a big increase in the level of water surface in the middle of the ocean, taking off from this level driving waves towards the coast. These waves moving too fast, and the wave speed depends on the strength of the earthquake its situation from the sea bottom. Its destructive power strength lies in that it suddenly appear to people on the beach, rising abruptly from 1.5 meters to approximately 40 meters and hits the coast with tremendous force could cover the land to several kilometers.

The tsunami waves have the ability to pass the entire ocean and also have the ability to maintain its full power during the journey, and this is where the danger lies that

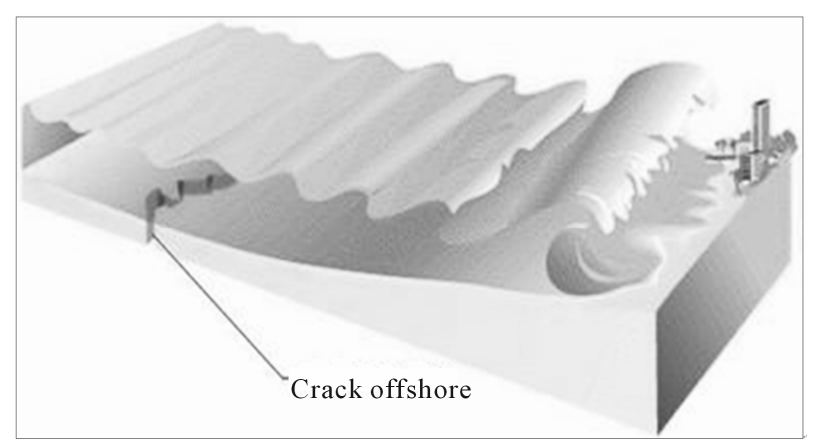

Figure 4. Crack in the bottom caused by the earthquake and offshore [9]. the wave energy does not decrease as it moves toward the beach, but maintain its level; because of the flexibility in energy transfer through the water molecules as observed in Figure 5, which shows the movement of the tsunami from the earthquake's center to of most the Indian Ocean coasts passing thousands of kilometers to hit the beach in a full capacity, leading to heavy losses in lives and properties.

\subsection{Geographic Distribution of Tsunami in the Mediterranean Sea}

When observing the earthquake on the earth map it is found that it is not distributed at random, but concentrated mostly in the major belts stretching long distances across continents and seas, and most of those belts powerful are the "Ring of Fire", extending along the east coast of the Pacific, and makes a belt along the west coast of the Pacific [11].

But in the Mediterranean Sea, belt goes a long across Africa, Europe and Asia. This belt is the most closing belts to the Libyan coast that extends from Morocco to Tunisia through Algeria. And from Tunisia extending north across the Mediterranean to Italy, Greece and Turkey, even China, and this belt is known as the belt of the Alps and contains about $21 \%$ of the world's earthquakes [12].

But earthquakes happen in places which have no relation to earthquake belts mentioned above. When the earthquakes are strong, they have serious consequences as the earthquakes that hit Turkey from time to time and in Algeria and elsewhere. Most of these earthquakes are not included tsunami for several reasons: the small size of the Mediterranean compared to the tsunami space requirements that give the opportunity to consist largely and destructive, as well as the basin containment of islands that working on cracking the waves, also shallower water in most of coastal areas. All of these factors preventing the occurrence of the devastating tsunami waves that hit the coasts of the Indian Ocean and the Pacific. However, tsunami was recorded in the basin several cases

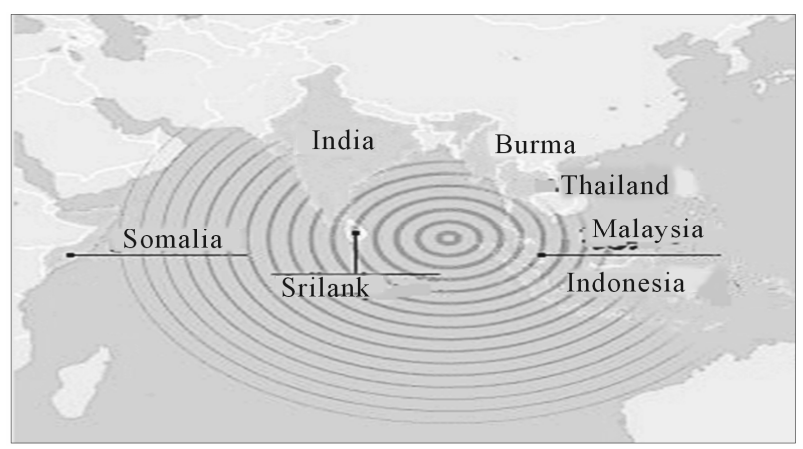

Figure 5. The tsunami transition between the Indian Ocean is full destructive power [10]. 
such as: the 29 February 1960 earthquake of Agadir (Mw 5.9) was the most damaging event in Morocco. The 10 October 1980 of El Asnam (Ageria) was the largest (Mw 7.3) recorded in North Africa and revealed $36 \mathrm{~km}$ of surface thrust faulting. The 21 May 2003 Zemmori earthquake (Mw 6.8) affected the area immediately in the east of the capital Algiers that experienced an average $0.50 \mathrm{~m}$ coastal uplift. The 1994 earthquake sequence struck the Rif region in Morocco and exhibited seismic.

In the Libyan coast until now researcher found no scientific evidence of benefit exposure of the Libyan coast tsunami in spite of the presence of foci of earthquakes, especially in the eastern region near the coast of Green Mountain. See Figure 6.

Figure 6 shows the coast of Libya divide into three main seismic focus areas, zone (III) represents the west coast of Tripoli in the east of the Tunisian border. And zone (I) is the coast of Sirt Gulf and stretching from Benghazi in the east to Khomess in the west. Zone (II) is the coast of Green Mountain.

Intensifying spots in zone (II) at the coast of Green Mountain in Figure 7 explains the section head of coastal zone (II). Notice a number of heavy seismic infesta

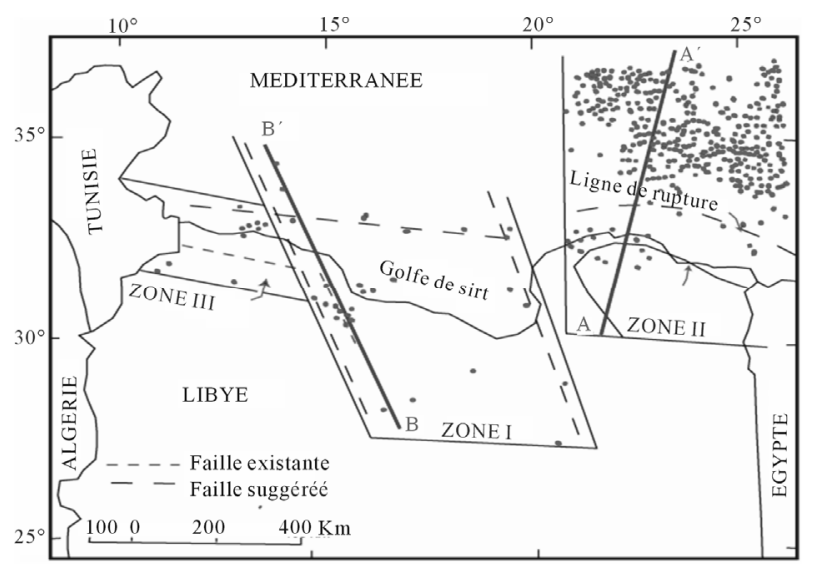

Figure 6. Distribution of seismic fuci in Libya [13].

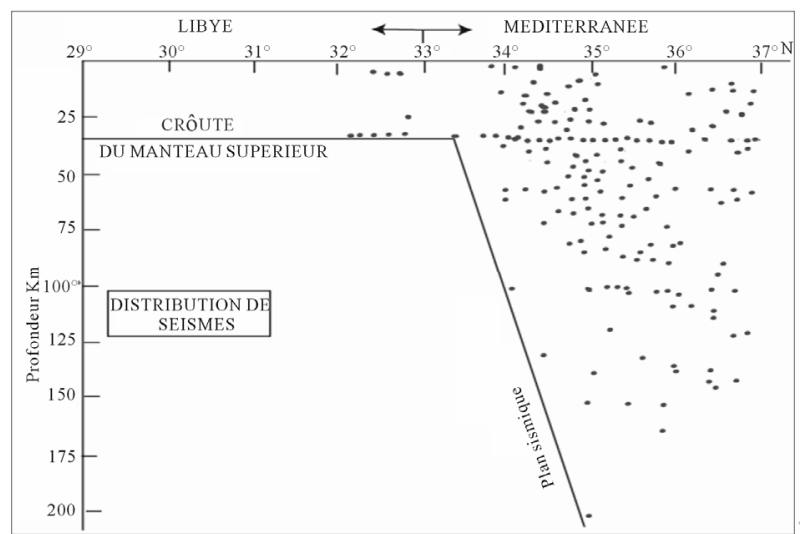

Figure 7. A vertical distribution of seismic foci in the region (II) [14] . The Coast of Green Mountain. tions, the vast majority of them in the sea, and the rest few (9 spots) on the mountain, and is characterized by focus mountain proximity to the surface where it does not exceed its depth from the surface of the mountain 40 $\mathrm{km}$. The seismic focus located in the sea spread over different distance from the Earth's surface to a depth of 200 $\mathrm{km}$.

In fact, despite the existence of a huge amount of seismic spots at the bottom of the Green Mountain coast, tsunami is not registered, and this does not mean it doesn't exist, and may for these waves have been monitored for the lack of attention to these phenomena, because they are not affecting directly on people lives in this region.

From Figure 8 zone (I), the area includes the Gulf of Sirt stretching from Benghazi east and even Misrata in the west, at least in this region the focus of earthquakes introduces Figure 8 distribution and few outposts in the sea (3 spots) at a depth approximately of $30 \mathrm{~km}$, and increase in land (9 spots) at a depth ranging between 20 and $40 \mathrm{~km}$, and this means less likely exposed to tsunami. The study area (Zuara coast): there is no any seismic focis, as to hotbeds coastline from Tripoli east to Ras Igedir west. See Figure 6, which makes us confident that no exposure to tsunamis.

\section{Wind Waves}

This type occurs almost every day in the water masses, except for static air days, which is rare, especially in a coast like Zuara coast, which is located within a transitional unstable climate. The size of waves depends on wind speed and the duration of blowing and other factors.

\section{How Wind Waves Are Brew}

When air pressure differs between two adjacent areas, the air travels from the region of high pressure to the other of low pressure. When it moves above the water surface, broken short capillary waves occur in at first by the direct contact between air molecules and the surface of water,

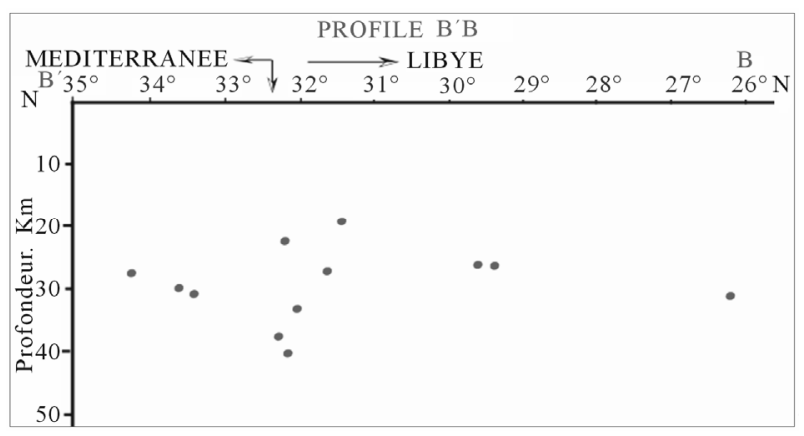

Figure 8. The vertical distribution of the seismic foci in region (II) [15]. 
just as the impact of blowing in a pot of water where wrinkles in the surface of water occur.

When an expert fisherman's in a small boat feels in the movement of wind and observes formation of small broken waves, he quickly goes back to the safe harbor. Because he knows that these small waves will be transformed into the bigger waves and the sea will become more eruptive.

When small capillary waves break, they build larger waves as they transport wind power to the water and as the period of wind gets longer, it gives the chance to the bigger waves to be formed and increases the length and speed of the waves to become equal to the speed of wind.

From Figure 9 it can be observed that the incurrence of wave top to wind directly helps to push orbits of water molecules forward, while the swirling air in the bottom of the wave causes intensive turning of molecules backward.

The expansion of water body or the distance that the wind is blowing (Fetch) also affects the wave size and speed, where Figure 10 shows how the smaller waves give the opportunity for waves to be greater as fetch increases.

In addition, to the period of wind and water extent, the volume and speed of waves also affected by wind speed; so there is a direct proportional that as the wind speed increases an increase of wave size and speed happens, as

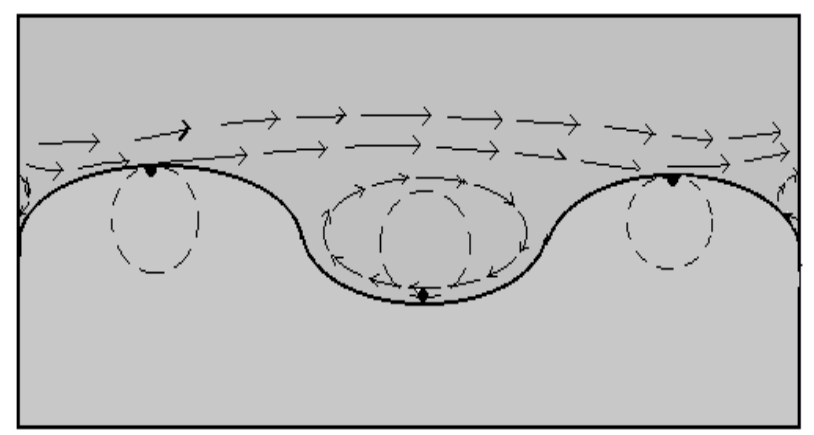

Figure 9. The role of wind for wave generation.

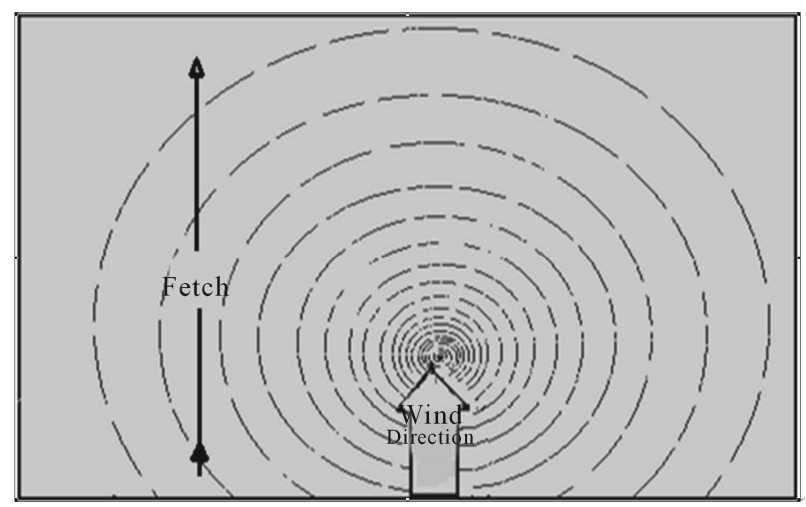

Figure 10. An increase in the size and speed of waves with the increased breadth of the flat fetch. it is concluded from Table 1.

Therefore, some specialists tried to determine the relationship among the wind speed, sea appearance and wave hight. One of those specialists is the British Admiral Sir Beaufort Franz in the British navy in 1806.

Through the previous view of wave types, it is clear that the coast of Zuara and the Libyan coast in general is exposed only to waves caused by wind, so we should give a general idea to the kinds of wind experienced by the study area.

\section{The Wind in the Year Seasons}

\subsection{The Wind in the Winter}

Due to the instability of weather in this season, for the reason of passing many air depressions, it is found that this region is nearly exposed to all kinds of wind. But these kinds differ in the percentage of recurrence, and the most prevailing winds in winter are the south-west wind, followed by southern winds, which blowing in this region at the front of depressions and characterized by severe coldness, particularly in the early morning. That is because it is coming from cold region, and then coming the north, north-west and west winds which blow in the rear of depressions these winds are often rainy on the coast. In addition, to the mentioned winds other wind types reach the coast such as: north-east and south-east and all these winds are dry.

\subsection{The Wind in the Summer}

This season is characterized by the stability of weather and clear climate as well as lack of rainfall and due to the centralization of an area of low pressure on the Sahara between the temperature rise in this season and high atmospheric pressure on the north of the Mediterranean Sea, the coming wind in this case mostly from the north and north-east. This means, from high pressure area to low pressure area, and the most prevailing wind is the north-east and north wind, respectively. This dry wind

Table 1. The effect of wind speed and fetch on the length and height and wave period [16].

\begin{tabular}{cccccc}
\hline $\begin{array}{c}\text { Wind distance } \\
\text { (Fetch) }\end{array}$ & $\begin{array}{c}\text { Wind speed } \\
(\mathrm{Km} / \mathrm{hr})\end{array}$ & $\begin{array}{c}\text { Length } \\
\text { of wave }\end{array}$ & $\begin{array}{c}\text { Period } \\
\text { of wind }\end{array}$ & $\begin{array}{c}\text { Wave } \\
\text { height/m }\end{array}$ & $\begin{array}{c}\text { Wave } \\
\text { period }\end{array}$ \\
\hline 20 & 20 & 2.4 & 0.3 & 0.4 & 4 \\
30 & 60 & 6.0 & 0.9 & 1.1 & 6 \\
40 & 140 & 10 & 1.6 & 2.6 & 8 \\
50 & 300 & 16 & 3.0 & 4.5 & 10 \\
60 & 500 & 23 & 4.5 & 7.0 & 12 \\
75 & 1200 & 42 & 9.0 & 14 & 16 \\
90 & 2600 & 69 & 15.0 & 25 & 20 \\
\hline
\end{tabular}


prevails all parts of this region and is working for the temperament of temperature for the reason that it is coming from lower temperature area as east winds. In addition, other wind types are rarely blowing as south east and Western winds.

\subsubsection{Wind in the Spring and Autumn Seasons}

The wind blows in these two seasons from all directions, but the most blowing winds come from the north east and east south. In this case the weather is characterized by its instability.

The most dangerous wind types on population is the wind blows in the end of spring season and the beginning summer season as well as in autumn sometimes. This wind is called "Gibly", which is a local nomination. This wind is characterized by its sever dry and high temperature, and in many cases is loaded with dust, as often calm at sunset and return next day, and may continue for several consecutive days in the same month. In March which considered the most month exposed to this type of wind, where the percentage of blowing reached $17.2 \%$ over 21 years [17]. The reason for blowing of this wind type is the depression on the Atlantic Ocean, which rushes to the East of the Mediterranean through the Strait of Gibraltar where Gibly wind gravitate to it, since its direction starting with south east then to south and eventually south west following the direction of depression coming from west in the east direction.

From the previous, it is clear that this coast area (study area) is exposed to the following wind types: 1) Northeast trade winds; 2) Southern winds (Gibly); 3) Trade north and north-western cold winds; 4) Breeze of sea and land.

\subsubsection{North East Winds}

This kind of winds prevails in summer and working to lower the temperature, but this kind causes the waves to buildup. The wind speed is usually slow in the morning and gradually increases to reach a maximum in the evening, so the fishermen take advantage of early morning in fishing operations.

\subsubsection{Southern Winds}

Southern winds are local winds blowing from the desert in the end of spring and the beginning of summer, as well as autumn season. When this wind kind blows, it causes a sudden rise in temperature as well as rapidly lowers the relative humidity. Gibly brings the blasting heat and dust storms from the heart of desert, accompanying by an increase of sea water temperature. It also works to calm the waves and still the sea water remarkably, to be a better atmosphere for trips and fishing.

\subsubsection{North and North-Western Winds}

This wind blows during winter, and in fewer cases during spring and autumn, as well as in front and back of the atmospheric depression invading the Mediterranean from west to east, causing a drop in temperature and rainfall. This wind sometimes brings polar winds causing the Perishing storm. It works to reduce the temperature of sea water to its lowest levels in winter. Also this type of wind causes a buildup of waves since this region is experienced to the highest and most serious waves on the maritime navigation in this season, leading to a decline in the number of trips sailing and fishing and lack of production and experiencing noticeable prices to rise during the winter months.

\subsubsection{Sea and Land Breeze}

During the day, the sun heats land, leading to heat the air which expands and rises to the top and pressure decreases. While on the sea the atmospheric pressure rises as a result of cooler water relative to the land, and so the air moving from sea to land is called the sea breeze. But at night the opposite occurs, since the land temperature drops less than water where air moving from land to the sea (land breeze). The following Table 2 shows the dates of sea breeze and land breeze in the area of study. The influence does not exceed one kilometer at the most and makes the strip adjacent to the beach area colder than the south areas, therefore, making this area as a haven for residents in the hot days.

\section{Wind Waves in Zuara}

The wind speed varies from time to time and from one region to another. In 1905 Beaufort classified wind by its speed and its relationship to waves into twelve classes. It starts from calm state (zero degree) and reaches the hurricane (Class 12). From Beaufort scale shown in Table 3, it can be noticed that waves grow higher and risk increases speed of $6 \mathrm{~km}$ per hour have light ripples without foam with wind speed. The waves that come with wind or crests, and the wind of speed $85 \mathrm{~km}$ per hour accompa-

Table 2. The time of sea and land breeze [18].

\begin{tabular}{cc}
\hline Time & Case of wind \\
\hline From sunrise to 9:00 & Stillness \\
$12: 00$ & Beginning of the sea breeze \\
$14: 00$ & Top of the sea breeze \\
$18: 00$ & End of the sea breeze \\
$20: 00$ & Beginning of the land breeze \\
$5: 00$ & Summit land breeze \\
Sunrise & End of the land breeze \\
\hline
\end{tabular}


nying high types in the form of chains collapsing on each other and impair vision.

Table 3 shows the highest speed of wind as relating to forming the highest waves. It is noticed that the highest speed Zuara city coast exposed to in the thirty years is 65 knots. This speed leads to the formation of high waves, which cancel all cruises for both ships and boats. These waves make a major threat to ships cruising at sea, but this region was exposed to this speed only once during the thirty years in November 1987. Dangerous speeds are

Table 3. The highest wind speed in knots for the period from 1970 to 2000 [19].

\begin{tabular}{|c|c|c|c|c|c|c|c|c|c|c|c|c|}
\hline \multirow{2}{*}{ Year } & \multicolumn{12}{|c|}{ Months } \\
\hline & 1 & 2 & 3 & 4 & 5 & 6 & 7 & 8 & 9 & 10 & 11 & 12 \\
\hline 1971 & 32.0 & 36.0 & 33.0 & 30.0 & 27.0 & 27.0 & 30.0 & 27.0 & 30.0 & 30.0 & 30.0 & 32.0 \\
\hline 1972 & 29.0 & 30.0 & 30.0 & 30.0 & 35.0 & 27.0 & 25.0 & 26.0 & 28.0 & 25.0 & 25.0 & 28.0 \\
\hline 1973 & 27.0 & 25.0 & 30.0 & 27.0 & 24.0 & 25.0 & 27.0 & 30.0 & 21.0 & 25.0 & 19.0 & 25.0 \\
\hline 1974 & 30.0 & 45.0 & 33.0 & 30.0 & 27.0 & 21.0 & 18.0 & 20.0 & 23.0 & 35.0 & 18.0 & 32.0 \\
\hline 1975 & 27.0 & 35.0 & 30.0 & 28.0 & 30.0 & 25.0 & 22.0 & 28.0 & 22.0 & 25.0 & 20.0 & 25.0 \\
\hline 1976 & 45.0 & 30.0 & 37.0 & 27.0 & 27.0 & 27.0 & 30.0 & 30.0 & 35.0 & 40.0 & 40.0 & 27.0 \\
\hline 1978 & 50.0 & 35.0 & 35.0 & 30.0 & 30.0 & 32.0 & 25.0 & 28.0 & 26.0 & 25.0 & 28.0 & 25.0 \\
\hline 1979 & 35.0 & 30.0 & 35.0 & 35.0 & 35.0 & 28.0 & 28.0 & 28.0 & 30.0 & 35.0 & 35.0 & 30.0 \\
\hline 1980 & 33.0 & 38.0 & 23.0 & 38.0 & 36.0 & 30.0 & 28.0 & 30.0 & 28.0 & 40.0 & 42.0 & 45.0 \\
\hline 1981 & 45.0 & 35.0 & 40.0 & 40.0 & 35.0 & 29.0 & 30.0 & 28.0 & 25.0 & 30.0 & 36.0 & 27.0 \\
\hline 1982 & 38.0 & 38.0 & 40.0 & 35.0 & 30.0 & 29.0 & 22.0 & 20.0 & 20.0 & 35.0 & 28.0 & 28.0 \\
\hline 1983 & 30.0 & 28.0 & 40.0 & 26.0 & 42.0 & 25.0 & 20.0 & 25.0 & 25.0 & 24.0 & 22.0 & 30.0 \\
\hline 1984 & 22.0 & 30.0 & 23.0 & 25.0 & 28.0 & 30.0 & 22.0 & 25.0 & 23.0 & 28.0 & 28.0 & 22.0 \\
\hline 1985 & 38.0 & 25.0 & 25.0 & 35.0 & 25.0 & 20.0 & 20.0 & 23.0 & 22.0 & 28.0 & 25.0 & 35.0 \\
\hline 1986 & 23.0 & 24.0 & 28.0 & 25.0 & 25.0 & 28.0 & 28.0 & 20.0 & 30.0 & 30.0 & 25.0 & 35.0 \\
\hline 1988 & 30.0 & 28.0 & 25.0 & 30.0 & 25.0 & 30.0 & 28.0 & 21.0 & 20.0 & 25.0 & 33.0 & 35.0 \\
\hline 1989 & 21.0 & 32.0 & 30.0 & 25.0 & 30.0 & 30.0 & 20.0 & 21.0 & 22.0 & 29.0 & 18.0 & 28.0 \\
\hline 1990 & 32.0 & 21.0 & 28.0 & 30.0 & 35.0 & 27.0 & 25.0 & 24.0 & 18.0 & 20.0 & 35.0 & 35.0 \\
\hline 1991 & 25.0 & 20.0 & 29.0 & 30.0 & 25.0 & 30.0 & 20.0 & 20.0 & 20.0 & 25.0 & 23.0 & 32.0 \\
\hline 1992 & 19.0 & 25.0 & 30.0 & 25.0 & 28.0 & 26.0 & 25.0 & 18.0 & 18.0 & 20.0 & 24.0 & 22.0 \\
\hline 1993 & 22.0 & 27.0 & 22.0 & 30.0 & 25.0 & 27.0 & 20.0 & 18.0 & 24.0 & 22.0 & 20.0 & 27.0 \\
\hline 1994 & 35.0 & 27.0 & 28.0 & 35.0 & 21.0 & 20.0 & 21.0 & 20.0 & 20.0 & 20.0 & 25.0 & 23.0 \\
\hline 1995 & 25.0 & 18.0 & 22.0 & 32.0 & 18.0 & 25.0 & 20.0 & 21.0 & 21.0 & 23.0 & 21.0 & 19.0 \\
\hline 1996 & 17.0 & 30.0 & 22.0 & 27.0 & 21.0 & 17.0 & 25.0 & 20.0 & 28.0 & 35.0 & 27.0 & 35.0 \\
\hline 1997 & 20.0 & 25.0 & 25.0 & 39.0 & 27.0 & 20.0 & 25.0 & 19.0 & 30.0 & 18.0 & 28.0 & 30.0 \\
\hline 1998 & 29 & 20 & 37 & 29 & 24 & 20 & 20 & 20 & 25 & 25 & 20 & 25 \\
\hline 1999 & 28 & 24 & 25 & 25 & 20 & 28 & 23 & 20 & 20 & 19 & 20 & 30 \\
\hline 2000 & 20 & 25 & 21 & 24 & 23 & 20 & 22 & 20 & 20 & 25 & 15 & 23 \\
\hline
\end{tabular}


found but less severe than the speed mentioned and frequently happen. These speeds are 40 to 50 knots which are repeated every three to four years, but recurrence speeds are 20 to 30 knots.

This leads to the cancellation trips, especially the small, medium and large fishing boats which are the most important boat types.

\section{The Effect of Waves on the Human Activities}

Waves are the most common types of surface marine movement that affect the sea human activities, either directly as in the field of fisheries and maritime navigation, or indirectly, as the positive impact of waves on the marine environment by providing sea with oxygen and cleaning of contaminants. The following is some clarifications these effects:

\subsection{The Impact on Marine Navigation}

The navigation is the most human activities affected by waves as they deal with it directly. This effect of waves is on several nautical things, including:

\subsubsection{Impact on the Cruise Possibility}

Through interviews with some navigation experts from fishermen in Zuara port for fishing and crew they said that there is a specific wind speed that sailing can not be done with it, because this speed will lead to the formation of high waves which make boats and ships to sink, but the larger size of boat the less risk of sinking. The navigation trips are cancelled in wind speeds [20], as follows:

1) Ships

a) Cancel the trips of ships with size of 200 meters, if wind speed increases above 50 knots;

b) Cancel trips of ships with size of 100 meters, if wind speed increases above 35knots;

c) Cancel trips of ships with size of less than 100 meters, if wind speed increases above 30 knots.

2) Boats

a) Cancel trips of boats with size of 20 to 30 meters, if wind speed increases above 25 knots;

b) Cancel trips of boats with size of less than 20 meters, if wind speed increases above 20 knots;

c) Cancel trips of boats with size of less than 15 meters, if wind speed increases above 15 knots.

\subsubsection{Impact on the Speed of Ships and Boats}

The impact of waves is not only to cancel trips, but on the speed of boats. High waves may allow making trips, but boats will take twice the time that should take when do not face waves, and this means the boat sailing in the opposite direction of the waves. On the other hand, boats may shorten the time of travel when sailing in the same direction of wave movement. This issue needs to be carefully examined to determine the time of travel, taking into account the direction and speed of waves.

\subsubsection{Impact on the Fuel Consumption}

There is no doubt that the resistance of waves to boat body, when sailing in the opposite direction of waves, requires more power to push it forward. This power needs to increase the amount of fuel, to the extent that the boat journey may consume twice the amount of fuel consumed by the same trip, when it is moving in the same direction of waves.

\subsection{The Impact of Waves on the Ports and Harbors}

The most important thing in studying waves is to know the maximum height that waves can reach. In the studying area, waves should not be higher than bumpers to avoid extreme impact on the boats lying in those ports and harbors. So, studying waves can help to determine the height of quay or harbor.

\subsection{The Impact of Waves on Ship Design}

Ship design is similar to building design in terms of size that the strongest earthquakes can not break small kennels. On the other hand, long buildings should be flexible as earthquakes or storms can not break or overturn them. Small boats should be built as solid as possible and big ships should be flexible to withstand shocks and sprains due to weight.

In contrast, while it is commonly believed that the high raging sea waves are non-destructive to ships, long waves compared with the length of the ships are suffering from circular movement of water molecules, similar to cork suffering, and modern ships can withstand small needed bending and twisting, that are built on the basis of flexibility. Mostly, metal sheets on the hulls of ships are built in interference with each other as shells found on the body of fish that it can slide on each other, and leak water. This water is often used in cooling the engine and loads.

One of the things destructing ships is the broken waves. In areas of storms, where waves get bigger and broken as well, water that slides to the front of wave, does not move in circular movement, but it may considered within the amount of water which moves at a high speed in the direction of ship.

This amount of water can strongly destroy parts of ships, which lie above the main surface of the ship or break the hull, especially if strongly pushed to the side of the ship which is above the water surface. So the captain will direct the ship to the reverse direction of wind in the storm. This is because the bow of ship can withstand the 
wave shocks better than any other parts in the ship. But away from the center of the storm it does not matter in any direction the ship goes, that there is no broken waves and islands. From the other point of view, the study of waves is also important in ship design, where a large amount of energy for pushing ship goes in forming waves. Waves which are behind the ship represents the lost energy from the ship, where the energy is transferred away to be stored at the end, when waves is broken on the distant shores. Thus, the key in designing an efficient boat is to make a body which leaves the smallest impact possible at the economic speed and this can be in the bow, front shoulder, back shoulder and steering wheel. The idea is to get a bigger destructive overlap possible within the waves generated from these points, and thus ships leave the smallest impact possible. So the less energy gives the effect, the more efficient ship.

\subsection{Reduction of Wave Activity}

In times gone fishermen have realized that they can reduce rough seas on their boats by slowly oil leaking above the water, and the interpretation due to the property of surface tension in liquids, which makes water surface coherent. For example, the mosquito stands on the water surface, and when oil is put on the water doing the action of a rubber plate water surface surrounding the boat, which helps to prevent wave from breaking by the same speed it breaks up as it should.

In addition to this, waves can be calm by putting anything else in water which helps to undermine the wave energy. Ice or waste floating on the surface can do this, and also mud or sea grass can help. In fact, the artificial kelp is made in order to help making waves more calm in places, where the seaweed does not live, but all these solutions are done in a limited area especially boats mooring areas or the descent or ascent of their passengers.

\section{Conclusions}

\subsection{The Results of the Study}

1) There are several types of waves as they occur, and the most important waves are waves of wind and hurricanes, waves of earthquakes and volcanoes, and waves of landslides.

2) The Mediterranean basin is exposed to earthquakes on most coasts and infrequent to accompany tsunami waves such as Algeria and Morocco coasts.

3) Most of the earthquakes do not include tsunami for several reasons: the small size of the Mediterranean compared to the tsunami requirements of space that give the opportunity to consist large and destructive, as well as the basin contains islands that work on cracking the waves, also shallower water in most coastal areas.

4) The Libyan coast is exposed to earthquakes except
Zuara coast and no attestation for tsunami waves.

5) Waves in Zuara coast are of the wind wave type.

6) The size and speed of waves in Zuara coast depend on the wind speed and direction, and its blowing time.

7) The largest size of waves is formed in winter by the cause of north-west winds, which the fastest winds experienced by the Libyan coast.

8) The best days of navigation and fishing are the days of south wind where the sea is calm.

9) Zuara coast is exposed to wind speeds somewhat dangerous because they tend to stop the trips of ships and fishing boats. The highest wave speed reached in Zuara coast in 30 years is 65 knots.

10) Zuara coast is the best area for maritime navigation along the Libyan coast, because it is protected from the north-west wind by the Tunisia coast, which is advanced northward from the west, as well as shallow water and long distance, which makes the waves to be broken far from the coast and makes the coast quiet, compared with the east and middle coast of Libya.

\subsection{Recommendations}

1) Creation of a modern observatory equipped with marine monitoring devices, whereas the current meteorological station is not designed to monitor the marine weather events. Thus fishermen in western Libya depend on the marine bulletins broadcast by the media in Tunisia.

2) Providing free meteorological data to the researchers, and not withheld from them, and the abolition of fees imposed on the researchers for these data.

3) This research is an initial step to study waves and the results are preliminary, and it should be followed by more steps under the guidance of students to study such topic.

4) The waves in Zuara coast have the smallest danger along the Libyan coast and it should take the advantage of this feature and support the fishing and commercial activity by and paying attention to Zuara port from its size and the fleet size working in it.

5) Arranging for courses in marine meteorology for all fishermen and managers of marinas, and fishing licenses should be granted only after attending these courses.

\section{REFERENCES}

[1] J. O. Algraeo, "Physical Properties of the Waters of the Libyan Coast,” Unpublished, p. 100.

[2] www.google.com/imgres?q=Zuara+MAP

[3] J. O. Algraeo, "Physical Properties of the Waters of the Libyan Coast," Unpublished, p. 88.

[4] J. O. Algraeo, "Physical Properties of the Waters of the Libyan Coast," Unpublished, p. 4.

[5] A. Lefevre, "Seas and Oceans," Champers World Library, 
Glasgow, 2004.

[6] http://cdip.ucsd.edu/?nav=documents\&xitem=waves\#irre gular

[7] K. Isitso, "Oceangraphy," The National Library in Baghdad, 1986, p. 492.

[8] K. Isitso, “Oceangraphy,” The National Library in Baghdad, 1986, p. 493.

[9] http://ts2.mm.bing.net/th?id=H.4558876844296177\&pid= $1.7 \& \mathrm{w}=227 \& \mathrm{~h}=112 \& \mathrm{c}=7 \& \mathrm{rs}=1$

[10] www.Abonawaf.com

[11] E. Almquili, "Hydro Geomorphological Risks,” Dar Shomoa al Takafa, Azzawia, 2003, pp. 82-83.

[12] J. O. Algraeo, "Physical Properties of the Waters of the Libyan Coast,” Unpublished, p. 4.
[13] A. J. jusqu’à, “Geology of Libya,” 1977.

[14] Campbell, et al., “The Geology of Sirt Basin,” 1968, p. 659.

[15] Campbell, et al., “The Geology of Sirt Basin,” 1968, p. 658.

[16] K. Isitso, “Oceangraphy,” The National Library in Baghdad, 1986, p. 521

[17] K. Isitso, “Oceangraphy,” The National Library in Baghdad, 1986, p. 523.

[18] Libyan NAtional Meteorological Center-LNMC.

[19] Central Department of Meteorology/Tripoli

[20] A Personal Interview with a Shipmaster Nadm Mustafa Naji, 6 April 2012. 